\title{
Teaching a Second or Foreign Language Based on Literacy Notions
}

\author{
Rama Dwika Herdiawan \\ Rama_dwika@yahoo.co.id \\ S1 English Language Education \\ Majalengka University
}

\begin{abstract}
Nowadays, litearcy has become the most prominent issue which must be paid attention in terms of second or foreign language teaching. In addition, this can be a prospective paradigm for the purpose of building the innovative teaching and learning process as well as enhancing the studetns' schemata in relation to reading and writing particularly. Therefore, this study is aimed to describe as well as prove whether the notions of literacy is appropriate or not for teaching second or foreign language, on the other hand, it also presents a number of relevant theories and also previous studies which reflect notions of literacy its self. However, there are still handicaps as well as constraints towards the implementation of literacy in terms of non native language teaching, the finding in various studies show the evidences which are related to the function of literacy as supplementary sucject or course in certain schools or colleges. Regarding the study, literacy is considered to be the affective as well as innovative strategy that can function to assist the students in acquiring the second or foreign language. Thus, notions of literacy not only conveys the traditional limits of reading and writing skills but also beyond the skills of text-centric literary interpretation.
\end{abstract}

Keywords: Teaching a Second or Foreign Language, Notions of Litearcy

\section{Introduction}

Nowadays, teaching a second or foreign language has been shifted over the years. As a result, the shifts bring the innovation as well as breakthrough in terms of the development of the teacher and students' schemata in teaching and learning process. Moeller et.al (2015) also state that Foreign language learning and teaching have undergone a signifiant paradigm shift as a result of the research and experiences that have expanded the scientific and theoretical knowledge base on how students learn and acquire a foreign language. One of them is closely related to literacy skills which conveys a broader scope of foreign language teaching and learning such as the discussion of relatioship between reaaders, writers, texts, culture, and language learning. Traditionally, it is defined as the 
ability to read ans write. However, it not only deals with the terms 'reading and writing' but also relating them to the social contexts of use and also the framework of reading and writing. It is also mentioned by Kern (2000), who states " a focus on literacy, by considering reading and writing in their social contexts of use, frames reading, and writing as complementary dimensions odf written communication, rather than as utterly distinct lingyistic and cognitive processes". In other words, literacy can be defined differently based on the social context of certain communities who engage in it. Furthermore, every school in indonesia has implemented the intructional activities which emphasizes on building the students' literacies by giving them opportunities to read and also write some materials dealing with literary content.

Mostly the instructional programs done by certain school, college, and also informal educational institutions whose purposes to foster students' competence in the areas of literacy. Their focus is providing the basic ability in terms of reading and writing particularly. In relation to the statements, Kern (2000) also mentions that most foreign language program aim to develop students' competence in both these areas. They focus on basic ability in reading and writing in introductory and intermediate courses, and on litearcy and cultural knowledge in advances courses. Meanwhile, Clark (2013) states that Literacy is central to the curriculum for English, from the initial teaching of reading and writing at primary stages of schooling through to the ability to read and write the range of academic genres or styles through which the subject knowledge of all subjects is realised at secondary level and beyond. It clear that literacy has become the main consideration to the curriculum for English particularly in Indonesia. In addition, the curriculum designers plan to create the content which is related to literacy perspectives. On the other words, literacy practices can be a constructive solution for the students to solve a number of problems when they develop their prior knowledge, skills, and also strategies in the literacy areas. It is in line with the statement from Volger et.al (2013) who mention “ Individuals adept at new literacy practices construct creative solutions for problems they encounter using the knowledge, skills, and strategies they have developed in other literacy contexts, reinventing communication practices that will afford them effective participation. For those who are not as adept in such contexts, full participation may be fraught with missteps".

Basically, literacy is compatible with teaching a second or foreign language because it covers the related contexts in terms of second and foreign language education. In addition, it is connected to a number of current issues in the language teaching professions such as theories of language acquisition, roles of linguistics, teaching culture, and also role of technology (Kern, 2000).

In terms of socio-economic nature of literacy, reading and writing are about the interpretation of language or meanings when these are realised as visual signs. A sign is something we hear, see, touch or smell and which refers 'to something other than 'itself (Johansen and Larsen cited in Holme, 2004). Thus, literacy closely deals with socio-semiotic contexts which focuses on visual signs 
in the social activity. Basically, the people usually deliver the meanings through the signs in order that the other ones are supposed to interpret them directly. According to Holme (2004), literacy deals with activities that emerge from the processes of encoding and decoding language and meanings as visual signs. The nature of these processes, whether they are perceived as operating in language, mind, society, economy or across history, can not be affected by the type of signsystem in which they must finally reside. It is clear that literacy not only deals with the visual signs but also the other aspects such as mind, society, economy or across history.

\section{Discussion}

Regarding the previous part, the litearcy notions are also considered to be crucial to the development of second or foreign language teaching and learning. It means that the role of literacy has brought a number of relevant outcomes in it and also affected the goals of embodying an effective instructional activities which is concerned with the importance of involving literacy as tool to accelerate the students' understanding towards the content of the material. In relation to the importance of literacy, there are a number of previous studies which totally reflect it by showing the findings as the evidences in terms of teaching second or foreign language teaching and learning using literacy notions.

Clark (2013) investigated the research entitled "A Sense of Place: Variation, Linguistic Hegemony and The Teaching of Literacy in English" which focuses on exploring tensions and discussing the implications and possibilities for the teaching of English and literacy. The findings reveal that addressing the issues raised by pupils' cultural-linguistic realities which are different from those of mainstream English culture, whether it be in South Africa, the United States or England, are complicated and not straightforward. It may seem to be educationally liberating to ecologise local literacy practices as exemplified by Wesbank, or to suggest incorporating the work of Hip Hop poets into the curriculum in place of canonical poets as exemplified by Turner Middle School. Moreover, Literacy practices influenced by linguistic ecology can become restricting rather than enabling, and literacy practices such as the ones outlined above at Wesbank run the risk of creating an almost impossible leap for their students to make when faced with the world beyond Wesbank. This is because there is a mismatch between the microcontent, which arguably is acceptable as a local ecological form of English within the local context, and the macro-sociological level in the world beyond Wesbank, where it is not. The hegemonic practices that underpin literacy at Wesbank are too far misaligned with those that underpin what it means to be literate in the world beyond Wesbank. Equally, arguments for excluding the study of canonical poets are based upon the very notion that is criticised, made on the basis of including the work of previously excluded Hip Hop poets on the basis of the exclusion of all other poets. Based on the a number of findings, it can be concluded that the proper teaching about language that leads to the appropriate teaching supporting the acquisition of initial literacy should be continued as part 
of teaching subject knowledge in relation to all curriculum subjects up to public examination. In addition, such as adapting literary practices or curriculum content in restricting ways for whatever the reason, is to deny disadvantaged pupils the chance to succeed and to impact upon linguistic landscapes in conscious, creative and challenging ways should they so wish.

Meanwhile, Wilson et. al (2014) investigated "Middle School Teachers' Discipline-Specific Use of Gestures and Implications for Disciplinary Literacy Instruction". The data, which included field notes and photographs from 354 lessons and 151 video-recordings of lesson segments, were analyzed using constant comparative methods and multimodal concordance charts. The analyses indicated discipline-specific differences in types of gestures, frequency of gestures, and centrality of gestures to the teachers' messages. Earth science depended on a variety of iconic and deictic gestures, the latter of which was also common in mathematics. Communications in language arts and social studies commonly included non- essential action gestures that mimicked the movements of characters and historical figures. This study modifies existing claims of the importance of gestures in teaching, suggesting that gestures can play relatively central or minor roles in communicating disciplinary concepts. It concludes with implications for disciplinary literacy instruction that more rigorously accounts for the role that gestures play in disciplinary learning.

Volger et. al. (2013) investigated "A Microgenetic Analysis of Classroom Discussion Practices: How Literacy Processes Intermingle in the Negotiation of Meaning in an Online Discussion". In this research, this study was focused on the process by which the conversation was created. Using screen-capturing software, the on-screen actions of the nine participants in an online classroom discussion were recorded and analyzed for evidence of reading, writing, and thinking processes. Retrospective interviews were conducted with three of the student participants for additional insights into these processes. A triangulation of data sources reveale participants engaged in at least three distinct patterns of reading, writing, and thinking, with some participants fluidly moving between these patterns throughout the conversation. The three patterns were described as follows: (a) a methodical reading of most messages, and composing of responses occurring as the reader/writer. The findings reveal that participants may vary in their literacy processes, there are many available paths to contribute effectively and to develop understandings from a classroom discussion that takes place online. Furthermore, they demonstrated the variety of ways in which participants in an online discussion work to co-construct what becomes a publically shared conversation. As the transcript of a completed online discussion linearly displays the messages in chronological order, it is easy to be seduced into thinking that production of the conversation similarly follows a sequential pattern. One student in this study displayed such a pattern; however, the other participants showed other ways of interweaving iteracy processes. This finding allows us to appreciate these participants' remarkable abilities for interweaving literacy processes in such a dynamic manner. 
Based on the previous studies mentioned above, it is clear that teaching second or foreign language through building the literacy skills can guarantee the students and also teachers to develop themselves in understanding the material content as well as their schemata dealing with language teaching and learning.

Regarding literacy's use of language, Holme (2004) metions that if litearcy is partly a visual sign system it also bound up with an even more complex use of sign:namely, language. Therefore, the written language is totally different from spoken language because the people mostly produce various kind of language when speaking to each other. In addition, the written one has become the crucial point in relation to literacy notions. In this case, literacy study has limitation as a system of communicative exchange which has no reference to how it impacts upon the minds that communicate (Holme, 2004). This is the actual evidence which indicated that literacy affects the people minds in communication as well as making meanings. Moreover, the social context can be influential effect towards the implementation of literacy in terms of second or foreign language teaching. And mental existence also provides the prominent thought about the nature of reading and wiriting.

\section{Conclusion.}

Becoming literate is the result of learning literacy in terms of achieving a particular reading and also writing performance. It is also appropriate to be implemented to the second or foreign language teaching and learning which aims to enhance the teachers and students' competences in relation to social contexts as well as the dimentions of communication its self.

Therefore, literacy is categorised as basic ability that must be possesed by the students particularly in order that they can develop their cultural and cognitive skills. It is also related to contextual factors in which focus on how people in different communities produce and use texts in different ways. Thus, notions of literacy not only conveys the traditional limits of reading and writing skills but also beyond the skills of text-centric literary interpretation.

Teaching second or foreign language through building the literacy skills can enable the students and also teachers to develop themselves in understanding the material content as well as their schemata dealing with language teaching and learning. However, there is still lack of implementation of literacy notions which affects achieving the goal of teaching a second or foreign language particularly. Thus, literacy is closely related to socio-semiotic contexts which focuses on visual signs in the social activity. Basically, the people usually engage the meanings through the signs in order that the other ones are intended to interpret them directly. The nature of these processes on decoding and decoding the language, whether they are perceived as operating in language, mind, society, economy or across history, can not be affected by the type of sign-system in which they must finally reside. It is clear that literacy not only deals with the visual signs but also the other aspects such as mind, society, economy or across history. On the other hand, mental existence is the actual evidence which indicated that literacy affects 
the people minds in communication as well as making meanings. Moreover, the social context can be influential effect towards the implementation of literacy in terms of second or foreign language teaching. And mental existence also provides the prominent thought about the nature of reading and wiriting.

\section{References}

Clark, U. 2013. A Sense of Place: Variation, Linguistic Hegemony and The Teaching of Literacy in English. English Teaching: Practice and Critique, September, 2013, Volume 12, Number 2, page. 5875.

Holme, R. 2004. Literacy:An Introduction. Edinburgh: Edinburgh University Press.

Kern, R. 2000. Literacy and Language Teaching. New York: Oxford University Press.

Moeller, et.al. 2015. Foreign Language Teaching and Learning. Faculty Publications: Department of Teaching, Learning and Teacher Education. Paper 196.

Holme, R. 2004. Literacy: An Introduction. Edinburgh: Edinburgh University Press.

Volger et.al. 2013. A Microgenetic Analysis of Classroom Discussion Practices: How Literacy Processes Intermingle in the Negotiation of Meaning in an Online Discussion. Journal of Literacy Research 45(3) $211-239$.

Wilson et.al. 2014. Middle School Teachers' Discipline-Specific Use of Gestures and Implications for Disciplinary Literacy Instruction. Journal of Literacy Research, 2014, Vol. 46(2) 234-262 